\title{
Analysis of the Global Impact of the Pandemic (COVID-19) on Construction Industry: Possible Scenarios
}

\author{
Andualem E Yadeta ${ }^{1 *}$ and Digvijay Pandey ${ }^{2}$ \\ ${ }^{1}$ Department of Construction Technology and Management, College of Engineering, Madda Walabu University, Bale Robe, Ethiopia \\ ${ }^{2}$ Department of Technical Education, Institute of Engineering and Technology (IET) Lucknow, India
}

*Corresponding author: Andualem E Yadeta, Department of Construction Technology and Management, College of Engineering, Madda Walabu University, Bale Robe, Ethiopia.

Received Date: August 03, 2020

Published Date: October 05, 2020

\begin{abstract}
After the first infection of the Novel Coronavirus Disease (COVID-19) pandemic in December 2019 in Wuhan city in China, it is spreading all over the world. Currently the pandemic cases are increasing globally and its impact on many industries including the construction is increasing. In the case of construction, projects of all types and sizes are at risk and industry participants must consider the impacts the pandemic that may have on projects. These days, the health warning so often heard is "wash your hands". From the construction industry health perspective, the current warning for stakeholders is "read your contract" prior to proceeding to the next steps. This study assessed the possible impacts of COVID-19 on construction industry with two proposed scenarios namely; 'Force Majeure' and Changes in Law'. From the scenarios, remedies provided to the stakeholders in construction industry from the globally applicable contract forms including FIDIC, JCT or NEC provisions on how to mitigate the impact of the pandemic on the industry. The study attempted to provide guidance to the industry stakeholders, to policy makers, and authorized officials to manage the problem with their contractual provisions.
\end{abstract}

Keywords: COVID-19; Construction industry; Force majeure; Changes in law

\section{Introduction}

The Coronavirus (COVID-19) was declared on 11 March 2020 as a pandemic by the World Health Organization (WHO), as the disease becomes a global issue. Since its occurrence, no country has able to stop the spread of the virus and the global response to the pandemic is presenting difficult legal issues and challenges across all industries, including the construction industry. Presently, many countries around the world are suspending all non-essential businesses, which would cover most ongoing construction project sites. Based on observed events, construction industry is predicted to face difficulties with supply chain disruptions, claims, and labor shortages due to city-wide shutdown worldwide. Since COVID-19 is affecting every business and its impact on construction industry might be more reflective. As workers become infected, quarantined and sick, labor shortages could arise and this may cause delay and affects active construction projects. Most international contracts including the FIDIC forms have provisions making time of essence to the contract and surely the schedule of works is significant to most contracts. It is observed from the current situation that the pandemic is affecting the performance of construction projects in many countries worldwide. So the study is aimed to analyze the impact of COVID-19 on global construction industry performance, even though the case of the pandemic is currently less in developing countries. The study gives more explanation on contract management, as the world is in a critical pandemic period to implement construction projects. 


\section{Contractual Implications}

Currently, many construction and engineering projects globally are being affected by COVID-19 pandemic in various ways, and most of them are stopped [1]. It is possible to mention many factors which come into play with regards to the impact of the pandemic on the industry, with in numerous forecasted scenarios. This study takes the approach of outlining several possible scenarios to which relevant contracts are likely impacted. In most contracts, unforeseen events such as COVID-19 have contractual provisions regarding the consequences of these events. These provisions usually fall into two scenarios, namely; 'force majeure' and 'changes in law'. Force majeure was originated from the French civil law which has been introduced into English law contracts, where it remains a creature of contract and not a common law doctrine. Contractually, the term 'force majeure' refers to unforeseeable events at the time the contract was entered into, beyond the party's control, that cannot be prevented or overcome, and result in a party not being able to perform some or all of its obligations in the contract. The COVID-19 pandemic could thus be understood as a force majeure event. Under many forms of contract, including the FIDIC forms, a force majeure event would typically entitle a contractor to an extension of time for critical delay caused by the event, but not to compensation for costs incurred during the period of delay, except if agreed-upon circumstances. As always, the actual wording of the contract clause(s) is important for contract management. The other contractual provision for the unforeseen event concerns Changes in Law (directions given by public authorities) which is made to respond to the pandemic. This provision is relevant and may yield a different legal effect. By contrast with Force Majeure, Changes in Law provisions in construction contracts may confer a right to an extension of time for the contractor and/or compensation for the unavoidable costs incurred due to the Changes in Law as stipulated under Sub-clause 13.7 of the 1999 and 2017 FIDIC contract forms.

\section{Pandemics and force majeure}

Most internationally used construction contracts (for example, FIDIC, JCT, NEC) have specific Force Majeure protocols. But, there is no standard legal definition of Force Majeure. As such, the application of force majeure protocols in each contract will depend on interpretation of the precise wording used [2]. Typically, the Force Majeure clause will provide for a non-exhaustive list of unforeseen events and circumstances. Obviously, references to disease, epidemics, or pandemics would be useful to invoke the clause, however, terms such as "act of God" or "acts of government" or general wording such as "circumstances beyond the parties' control" could potentially be relied on in some instances. However, the standard form contracts do all contain provisions that deal in one form or another with the impact of unforeseen and exceptional events such as COVID-19. These provisions are included to provide a mechanism for controlling the impact of unforeseen events, such as COVID-19. The Force Majeure provisions in the 1999 FIDIC forms of contract are essentially the same for the Red, Yellow and
Silver Books. A party prevented from performing its contractual obligations by a Force Majeure event must give notice to the other party within 14 days of when it became or should have become aware of it. The party is excused performance of its obligations while prevented from doing so, and, in the case of the Contractor, may be entitled to further relief in the form of an extension of time and/or (in limited circumstances) additional payment. The 2017 editions of the Red, Yellow and Silver Books of FIDIC have replaced the Force Majeure provisions in the 1999 editions with a new clause entitled 'Exceptional Events'. However, this is a less profound change than the replacement of a Force Majeure clause would suggest since the 2017 definition of Exceptional Event is similar, though not identical, to the 1999 definition of Force Majeure.

\section{Pandemics and changes in laws}

COVID-19 is such an unprecedented threat that it has led to the introduction of a raft of governmental actions (i.e. 'advice' or 'recommendations') as well as new legislation around the world. There is therefore a strong possibility that the COVID-19 to trigger Change in Law entitlement under many construction contracts. As is the case with Force Majeure, the concept of a Change in Law and the available contractual relief is dealt with in different ways under the major standard form construction contracts. The 1999 FIDIC forms of contract provide that the contract price shall be adjusted to take account of any increase or decrease in cost resulting from a change in laws of the country in which the works are situated or in the judicial or official interpretation of the laws, made after the Base Date (being the date for the submission of the tender), which affect the Contractor's performance of obligations under the contract. In such a case the Contractor is entitled to claim for time and/or cost relief. The 2017 edition of the FIDIC forms of contract expands the scope of the change in law provision such that any changes in the terms of any permits, permission, license or approval or the requirement for a particular permit, permission, license or approval to be obtained after the Base Date entitles the Contractor to relief. Conversely, if there is a decrease in cost due to a change in law, the Employer is entitled to make a claim under the contract for an adjustment to the contract price.

\section{Methodology}

From the contractual implications of the industry, two scenarios were identified. Then a total of five baseline scenarios were formulated under each scenario. The process was gone through the five phases which includes identification of the scenario field, identification of key factors, analysis of key factors, 4) scenario generation, and 5) scenario transfer. Due to the spread of the pandemic, data were collected through a web-based system with an online survey worldwide. The Delphi method was used in the study to evaluate the most important and uncertain driving forces that form the baseline scenarios. The Delphi is an iterative process of data collection and analysis designed to search for consensus among the anonymous experts by a series of intensive 
questionnaires interspersed with controlled feedback. The goal of the Delphi survey is to prioritize the judged statements in order to identify the most important and uncertain driving forces that form the bases of the scenarios. In this context, responses of the experts can be analyzed by measures of central tendency and dispersion [3]. With the Delphi method in this study, a panel of experts was invited with online survey forms to respond anonymously to statements; that they are to estimate how certain developments could turn out in the future. The results of this initial round of inquiry were collected by a Delphi-team, which evaluates and processes them and sends them back again to the experts with the request that they again take a stand on the issues. In this way, the degree of consensus and/or dissent within the experts, and thus the degree of uncertainty of the knowledge at issue were determined over the course of a number of rounds of questions and answers. All answers collected from the construction industry experts for analysis of content and final future scenarios were prepared. In this study, the scenarios were presented in two categories, namely 'Force majeure' and 'Changes in law' each with five specific baseline scenarios. As a final round, all specialists were invited to add a comment to the final scenario. Then scenarios constructed based on all collected opinions, advancements and innovations proposed and agreed by the majority of the experts globally after the third round of the method. Then, each scenario was analyzed and the possible suggestions from contractual provisions were pointed out to mitigate the impact of the pandemic on global construction industry.

\section{Scenarios Analysis: The Impact of COVID-19 on Construction Industry}

Since COVID-19 pandemic is affecting the economy worldwide in every sector, the construction sector is already experiencing a slowdown as a result of the pandemic and stakeholders are reviewing their contract provisions either to submit claims or to mitigate them. Even though manageable construction claims due to the pandemic are expected throughout the duration of the pandemic, the impacts on the industry is predictable. Many organizations use international contract forms like FIDC, JCT, and NEC for their projects. Therefore, there are many events which come under Force Majeure and Changes in Law contract provisions in their contract, resulting in numerous possible impacts of the pandemic. To analyze these impacts, two scenarios with five baseline scenarios for each category were identified based on contractual provisions. Delphi survey is an important step to identify key driving forces and the direction of future events. To measure the importance of baseline scenarios or certainty of occurrence of events a Delphi survey was developed. The baseline scenarios were judged independently by each expert on measurement-type scale worldwide with Delphi method of scenario analysis as shown in Figure 1 below. For uncertainty, responses of the experts were measured on scale ranged from 1 (highly certain) to 5 (highly uncertain) and importance was measured on a scale ranged from 1 (least important) to 5 (highly important) (Figure 1).

In this research, responses of the experts were analyzed by measures of central tendency (arithmetic mean and median). The result of the first round was fed back to the experts including the measures of central tendency in order to investigate whether consensus increases or disagreement remains. After the consensus, an index value was obtained to evaluate importance of the driving forces, using the following formulae:

Index Value (IV) $=$ Actual obtained score $\quad$ X 100

Maximum obtainable score

The final index value (IV) was estimated by taking average figure of the index value of importance. Based on the index values the driving forces and their probable changes are prioritized. To evaluate the possible scenarios with the Delphi method, the questionnaire was elaborated into two categories each with five baseline scenarios (A1, A2, A3, A4, A5) representing 'Force Majeure' and (B1, B2, B3, B4, B5) representing 'Changes in Law' as shown in Figure $2 \& 3$ below (Figure 2, 3).

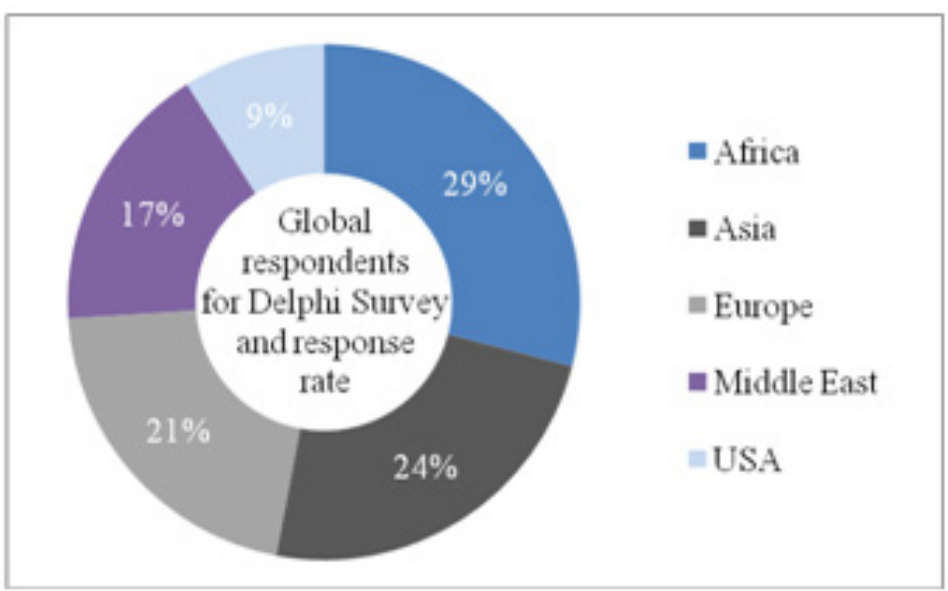

Figure 1: Global response rate for Delphi survey. 


\section{Index Value (IV) for Scenario-A}

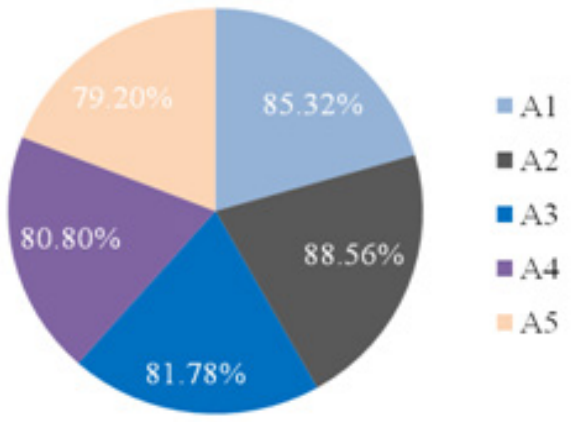

Figure 2: Index Value (IV) for Scenario A.

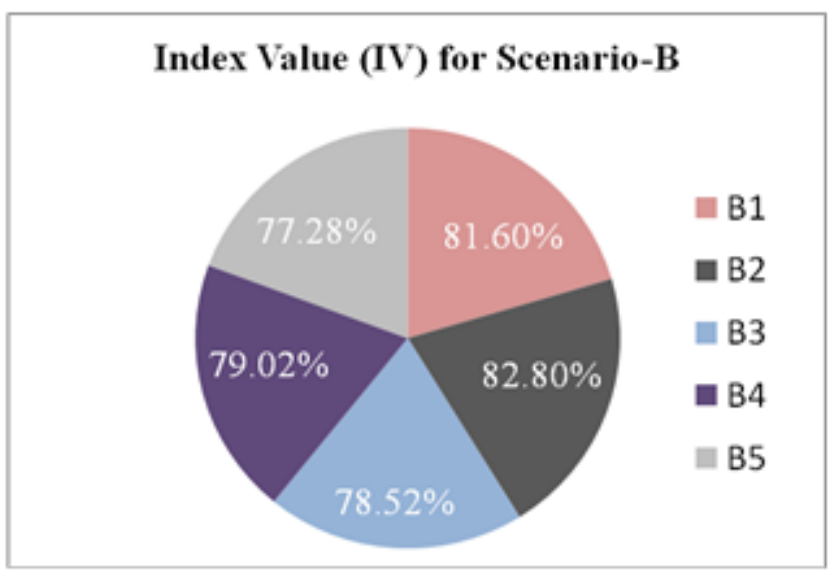

Figure 3: Index Value (IV) for Scenario B.

\section{Scenario A: force majeure}

As COVID-19 is neither under the control of any party, nor an event that any party could foresee before signing the contract, not an event any party may reasonably avoid and it is a situation that cannot be attributed to any side. However, while making this evaluation, it is also necessary to pay attention to the laws of country, which is applicable to the contract, as some national laws may not define this situation as a force majeure. The following five baseline scenarios are outlined to analyze the global impact of the pandemic on the industry to provide the relevant responses to mitigate them contractually.

1. As the COVID-19 affects the supply chain and the availability of workers to satisfy the contractor's scheduling and other obligations on construction projects, claims for delay, disruption and cost will certainly occur. Most standard form construction contracts do not include an express provision entitling the contractor to claim an extension of time (EOT) or loss and expense for delays and increased costs due to a pandemic itself. However, many entitle the contractor to relief for delays, and sometimes loss and expense that may result from, or are caused by, the occurrence of such an event. The construction industry globally, is currently suffering a shortage of labor (as a result of infection and resulting quarantine or self-isolation, or preventative measures to delay the spread of COVID-19) and shortages of plant and materials (due to delays in their importation or transportation). Some, although not all contracts, entitle the contractor to claim relief in these circumstances. Sub-clause 8.4 (d) in the Red and Yellow Books of FIDIC permit an extension of time (EOT), but not cost, where taking over is delayed by "unforeseeable shortages in the availability of personnel or goods caused by pandemic or governmental actions". Importantly, this relief is only available where the shortages cause delay to completion, i.e. critical delays to the works. COVID-19 has been declared a pandemic and therefore the restrictive measures and border controls imposed by many governments should be caught within "governmental actions". There is no country restriction as to where the pandemic took place, or as to which government took the action that caused the shortages. This relief is not available in Silver 1999 Book, but in Silver 2017 Book, it is available for unforeseeable shortages in the availability of employer-supplied materials. Under the JCT contract, the contractor is entitled to an extension of time where completion of the works or a section is likely to be delayed 
beyond the relevant completion date by a "Relevant Event". The list of Relevant Events does not expressly include global virus outbreaks such as COVID-19. As mentioned above, force majeure is listed as a Relevant Event so the contractor may be able to claim additional time in respect of delays caused by COVID-19, subject to the factual assessment and mitigation factors. Under the NEC contract, additional time and money are not treated separately but are instead assessed together as a "compensation event". There are a number of potential compensation events that might arise as a result of COVID-19, including compensation events for a failure by the client to provide something in time. In particular, clause 60.19 provides that there will be a compensation event when an event occurs which: "stops the contractor completing the whole of the works or stops the contractor completing the whole of the works by the date for planned completion showing on the accepted program and which neither party could prevent, an experienced contractor would have judged at the Contract Date to have such a small chance of occurring that it would have been unreasonable to have allowed for it." This provision may entitle the contractor to additional time and/or money as a result of the impact of COVID-19 on the works in the event of, for example, the need to self-isolate a material part of the workforce or the lack of materials as a result of shortages caused by the virus.

2. The contract can be terminated due to Force Majeure provisions, liquidated damages and other contractual terms during the pandemic period. Standard form contracts typically set out in detail the termination rights of each party. The right to terminate under a contract does not necessarily exclude the right to terminate at law. Relevant contractual termination rights in light of the COVID-19 emergency are likely to be those relating to a prolonged period of suspension, a prolonged "force majeure" and the prolonged effect of government intervention. Clause 16.2.1(h) of the 2017 Yellow Book of FIDIC entitles the contractor to give a notice of termination where a prolonged suspension instructed by the employer affects the whole of the works. A prolonged suspension is one that continues for more than 84 days (clause 8.12). A prolonged Exceptional Event that continues for more than the stated period entitles either party to terminate the contract (clause 18.5, 2017 Yellow Book of FIDIC). In addition, either party may terminate if any event arises outside the control of the parties that makes performance impossible or unlawful, unless the parties are able to agree on an amendment to the contract that would permit the continued performance (clause 18.6). The same comments apply as in relation to clause 91.5 of NEC4 ECC. Under JCT clause 8.9.2 of DB 2016, the contractor is entitled to terminate the contract following the expiry of the prolonged period stated in the contract during which "the carrying out of the whole or substantially the whole of the uncompleted works is suspended by reason of any impediment, prevention or default by the employer", subject to the contractor complying with the requirements of clause 8.9.3.
3. Either party is entitled to terminate the contract following the expiry of the prolonged period of suspension stated in the contract as a result of, among other things: Force majeure (clause 8.11.1.1, DB 2016); and the government or other local or public authority exercising statutory powers that directly affect execution of the works (clause 8.11.1.5, DB 2016). Under the NEC contract, where the project manager has instructed the contractor to stop, or not start, any substantial or all work and an instruction allowing the work to start or re-start, or removing work from the scope, has not been given within 13 weeks, either party may terminate if the instruction was not due to a default of either the contractor or the client. In other words, where it is a neutral event (clause 91.6, NEC4 ECC) and, clause 91.5 also entitles either party to terminate if they have been released under law from further performance of the whole of the contract.

4. In addition to contract provisions relating to scheduling and completion of works, the contractor and/or the employer will suspend the performance of the contract as a result of COVID-19. A force majeure provision typically operates by "suspending" performance of some or all of the contractual obligations of the party affected by the force majeure event. The exercise of statutory powers by a government or government entity may also have the effect of "suspending" performance of the works. Clause 8.9 of the 2017 Yellow Book of FIDIC provides that the engineer may at any time instruct the contractor to suspend progress of part or all of the works. Provided that the contractor is not responsible for causing this suspension, it is entitled to claim an EOT and additional cost. Clause 18.5 of 2017 Yellow Book stipulates that if execution of substantially all the works is prevented (suspended) by an Exceptional Event for a continuous period of 84 days or an aggregate period of 140 days (due to the same event), the right to terminate is triggered. Under clause 2.26.2.2 of JCT, the employer may instruct the contractor to postpone any work to be executed under the contract. If "the carrying out of the whole or substantially the whole of the uncompleted works is suspended for a continuous period of two months by reason of any impediment, prevention or default by the employer", this may ultimately trigger the contractor's right to terminate the contract (clauses 8.9.2 and 8.9.3, DB 2016). The parties may have agreed a different "suspension period" and parties should check the Contract Particulars. Under NEC clause 34.1, NEC4 ECC, the project manager may instruct the contractor to stop or not start any work. This is a Compensation Event entitling the contractor to claim an EOT and additional cost. If a clause 19 event under the NEC4 ECC stops the contractor completing the whole of the works by the date for planned completion shown on the accepted program and this delay is forecast to continue for more than 13 weeks, the client, but not the contractor, is entitled to terminate.

5. Since force majeure is an event which arises outside the control of the parties which makes impossible or unlawful for either 
or both parties to fulfill their contractual obligations, COVID-19 emergency frustrates the contract. If a contract becomes physically or commercially impossible to perform, the common law doctrine of frustration may apply to automatically discharge the parties from their obligations. However, the threshold for frustration at common law will ordinarily be significantly higher than the threshold for force majeure under a construction contract and English courts have repeatedly given the scope of the doctrine of frustration a narrow interpretation. However, there are a limited number of cases from other common law jurisdictions in which courts have determined that construction contracts have been frustrated. Frustration is also less likely to be successfully invoked where contracts contain a force majeure clause which addresses the scenarios that may arise as a result of COVID-19. In practice, the doctrine of frustration is likely to only be invoked in the most extreme circumstances and when the relevant construction contract does not have the ordinary mechanisms to deal with those circumstances.

6. In various contractual provisions regarding Force Majeure risks, COVID-19 will no longer qualify as force majeure for future projects. But parties may consider it as a force majeure due to unclear contractual provisions. Covid-19 will not be 'unforeseeable' for contracts that were recently concluded or those currently being negotiated. As with the timing of claim notifications, determining when COVID-19 became foreseeable and whether this impacts on a claim for Force Majeure needs to be considered carefully. As COVID-19 is unlikely to qualify as a Force Majeure event for future projects, parties need to allocate risks and manage future COVID-19 impact through the addition of so called 'Coronavirus Clauses'. Parties should also reconsider Force Majeure clauses in general to learn lessons from the COVID-19 pandemic, in particular to ensure the mechanisms take effect for similar pandemics in the future.

\subsection{Scenario B: changes in law}

This scenario considers contractual issues called "Changes in Law" (directions given by public authorities). Changes in Law on contractual provisions may yield a different legal effect [4]. When we look at FIDIC 13.7, the "Change in the Laws of the Country" expression here should be interpreted by considering FIDIC 1.1.6.5. Therefore, it should not be forgotten that any country's measures taken due to COVID-19 could create a "Change in the Laws" status under FIDIC 13.7 and an assessment can be made in this context when making a Force Majeure notification. Of course, this evaluation will lead to mutual discussion, but under FIDIC article 20.1, the evaluation of "Change in the Laws" should not be missing in order to request both time and additional payment. The main purpose of referring to Article 13.7 is to determine what the impacts of Force Majeure will be in terms of time extension and additional payments. Many legal systems (national laws) and FIDIC at the same time suggest that the Contractor may take additional time due to Force Majeure events. However, the problem is mostly on the financial part of issue. For example, if the project is delayed by 3 months due to COVID-19, there is a debate on which party will be the financial burden occurred due to delays, i.e. from the salary of the project managers to the warehouse rent for storing the materials. If we only make a Force Majeure notice, FIDIC will give us time extension, not money. Different arguments can be produced in legal systems. But when you look at 13.7, we are likely to win both money and time. In this scenario, the following five baseline scenarios were used to analyze the event for global impact of the pandemic on construction industry.

1. The local authorities/government will not promulgate any new piece of legislation or regulation banning construction activity or works on site. However, contractors will face difficulties in mobilizing their personnel, who fear for their safety, and in obtaining Goods due to issues in their supply chain. The Contractor may explore remedies under sub-clause 8.4(d) of the Red Book [5], Yellow Book [6], and Silver Book [7], sub-clause 8.5(d) of the Red Book [8], Yellow Book [9], and Clause 9.3(d) of the Gold Book of FIDIC, which provide for an entitlement to an Extension of the Time for completion (EOT) in case of "unforeseeable shortages in the availability of personnel or Goods (or employer-supplied materials, if any) caused by pandemic or governmental actions". Under Silver Book [10], the contractor is entitled to an EOT only in the event of unforeseeable shortages in the availability of employer-supplied materials, if any, caused by pandemic or governmental actions. No similar provision is provided under Silver Book [7], as this is a contractor's risk under that Book. No similar provision is found under Gold Book [11] either, but sub-clause 6.1(h), 7.3 and 10.4 can be investigated. The contractor should not forget that the above Sub-Clauses give an entitlement to an EOT only, and make no mention of any financial remedy, because that would depend upon the particular circumstances and whether the contractor can establish an entitlement to financial compensation elsewhere under the contract or at law.

2. Under the same circumstances as No. 1 above; the Contractors will suffer delays caused by the authorities (for example making repeated health and safety inspections on the Site). The Contractor may be entitled to an EOT under sub-clause 8.5 of the Red Book [5], Yellow Book [6], Silver Book [7] and Pink Book, in sub-clause 8.6 of the Red Book [8], Yellow Book [9], Silver Book [10], or in sub-clause 9.5 of the Gold Book, provided that the conditions set out in these sub-clauses are fully satisfied regarding any financial entitlement, same as in base scenario No.1 above applies.

3. The local authorities or government will promulgate changes to the Laws restricting construction activities and works on the Site. Contractors will still able to proceed with the Works, however they will suffer delay and or incurring additional cost as a result of those changes. If it is established that these actions by the local authorities or government are indeed considered as Changes in Laws of the country, then the contractor may seek remedy under 
sub-clause 13.7 of the Red Book [5], Yellow Book [6], Silver Book [7] or Pink Book, or under sub-clause 13.6 of the Red Book 2017, Yellow Book 2017, Silver Book 2017, and Gold Book. This is because of the contractor's obligation to comply with applicable laws as set out under sub-clause 1.13 of the Red Book, Yellow Book, Silver Book [7], or Pink Book, under sub-clause 1.14 of the Gold Book, or under sub-clause 1.12 of the Silver Book [10]. Such changes in laws may impose specific COVID-19 health and safety measures on construction activities (ongoing or on resumption) such as social distancing, supply of face masks and sanitizers, alternative arrangements for transportation, facilities, working hours for staff and labor, etc. Those changes may well be treated as a variation owing to the "adjustment to the execution of the works" that they may cause, or to the "changed or new applicable standards" that they may constitute. In the alternative, they may be treated as a claim event.

4. The local authorities/government will give or issue an order(s)/decree(s) preventing construction activities (including lockdown, curfew, inaccessible quarantined areas, etc.), and execution of the works on site will become impossible. Consequently, the Contractor and/or the Employer will be prevented from performing obligations under the Contract. Firstly, this situation may well be handled through the changes in Laws provisions set out under the contract, as explained under base scenario No.3 above. As to entitlements, the parties would have to look at which obligations are prevented by this Force Majeure/Exceptional Event, and notify accordingly as per sub-clause 19.2 (Red Book 1999, Yellow Book 1999, Silver Book 1999, or Pink Book), 13.2 [11-14] or 18.2 (Red Book 2017, Yellow Book 2017, Silver Book 2017, or Gold Book). First, consequence under the contract of a Force Majeure/ Exceptional Event is that it excuses performance of the said prevented obligations. Ultimately the Contractor may be entitled to an EOT for any resulting delay as per SC 19.4 (Red Book 1999, Yellow Book 1999, Silver Book 1999, or Pink Book), 7.3 (Gold Book 1999) or SC 18.4 (Red Book 2017, Yellow Book 2017, Silver Book 2017, or Gold Book). Financial entitlements appear unlikely; given that those arise only in conjunction with events of the kind referred to under SC 19.4 or SC 18.4 (as the case maybe).

5. There will be no changes neither in laws of the country nor real impact on the availability of personnel on the supply chain so far. However, the personnel of the Employer (including the Engineer or the Employer's Representative, as the case may be) will, as a precaution, working remotely and hence most of the time they will be away from site. As a consequence, contractors will suffer delay and/or incurring additional cost due to slow decision making. Unless the Employer is successful in arguing a Force Majeure or Exceptional Event case, the Contractor may explore remedies under sub-clause 8.4(e) of the Red Book 1999, Yellow Book 1999, and Pink Book, sub-clause 8.4(c) of the Silver Book 1999, sub-clause 6.1(k) and 7.3 of the Gold Book 1999, sub- clause 8.5(e) of the Red Book 2017, and Yellow Book 2017, subclause 8.5(c) of the Silver Book 2017, or sub-clause 9.3(e) of the Gold Book, which provide for an entitlement to EOT in case of any delay, impediment or prevention caused by or attributable to the Employer, or the Employer's Personnel (including the Engineer, or the Employer's Representative, as the case may be). The Contractor should bear in mind that the above sub-clauses give an entitlement to an EOT only, and make no mention of any financial remedy, because that would depend upon the particular circumstances and whether the contractor can establish an entitlement to financial compensation elsewhere under the Contract or at Law.

\section{Conclusion}

In this time, the COVID-19 pandemic has created an enormous amount of uncertainty in terms of contractual implications for those involved in construction industry. As a result, there is merit in the parties considering the negotiation of some contract amendments. A collaborative approach could potentially result in a more mutually commercially acceptable and less strictly contractual response to problems arising out of a COVID-19 impact. In adopting a collaborative approach, both parties to the contract would need to consider very carefully, the force majeure effects and the short and long term impacts of the pandemic. They will need to formally and carefully document any change and consider the impact of any change in law due to the pandemic in the country. Legislations affecting construction projects are being made daily to protect workers' health and safety. Changes in law being implemented now have clear public health consequences. What remains to be seen is the extent of the unintended consequences. Parties should carefully review the terms of their contracts, particularly any amendments to the standard forms, in order to determine the rights and obligations of both parties in relation to extensions of time and entitlement to additional payment as well as the obligations of the parties in the event of site closure. Collaboration and good communication will be key to managing the impact and steering projects through this period of uncertainty. To this end, parties should pay careful attention to the notice provisions under their contracts and give appropriate and adequate notice(s) as soon as practicable and within any contractual deadlines. The potential and actual impact of COVID19 on works in progress should be monitored carefully, mitigation measures taken where possible, and the suggested clauses in this study have to be referred.

\section{Acknowledgement}

None.

\section{Conflicts of Interest}

No conflict of interest.

\section{References}

1. Bailey J, Bouchardie N (2020) COVID-19: The Current Impact on Construction and Engineering Projects. Publication \& Events White \& Case LLP. 
2. Fiona N, Kelly H (2020) Construction Contracts - COVID-19 Impacts and Considerations. Dillon Eustace.

3. Grisham T (2008) The Delphi technique: a method for testing complex and multifaceted topics. International Journal of Managing Projects in Business 2(1): 112-130.

4. FIDIC Guidance Memorandum (2020) FIDIC COVID-19 guidance Memorandum to users of FIDIC standard forms of Works contract. Geneva: Switzerland. pp. 1-14.

5. FIDIC Red Book (1999) Conditions of Contract for Construction: For Building and Engineering Works Designed by the Employer. Geneva: Switzerland.

6. FIDIC Yellow Book (1999) Conditions of Contract for Plant and DesignBuild: For Electrical and Mechanical Works and for Building and Engineering Works Designed by the Contractor. Geneva: Switzerland.

7. FIDIC Silver Book (1999) Conditions of Contract for EPC/Turnkey Projects. Geneva: Switzerland.

8. FIDIC Red Book (2017) Conditions of Contract for Construction: For Building and Engineering Works Designed by the Employer. Geneva: Switzerland.
9. FIDIC Yellow Book (2017) Conditions of Contract for Plant and DesignBuild: For Electrical and Mechanical Works and for Building and Engineering Works, Designed by the Contractor. Geneva: Switzerland.

10. FIDIC Silver Book (2017) Conditions of Contract for EPC/Turnkey Projects. Geneva: Switzerland.

11. FIDIC Gold Book (1999) Conditions of Contract for Design-Build-Operate Projects. Geneva: Switzerland.

12. FIDIC Gold Book (2017) Conditions of Contract for Design-Build-Operate Projects. Geneva: Switzerland.

13. JCT (2005) Joint Contract Tribunal Standard Forms: Design and Building Contract. Sweet and Maxwell.

14. NEC4 (2017) New Engineering Contract: Engineering and Construction Contract (ECC). Thomas Telford Ltd. 